\title{
Survival Outcomes and Patterns of Recurrence in Patients with Stage III or IV Oropharyngeal Cancer Treated with Primary Surgery or Radiotherapy
}

Brock J. Debenham ${ }^{1}$, Robyn Banerjee ${ }^{2}$, Heather Warkentin ${ }^{3}$, Sunita Ghosh ${ }^{3}$, Rufus Scrimger ${ }^{3}$, Naresh Jha ${ }^{3}$, Matthew Parliament ${ }^{3}$

1. Department of Oncology, University of Alberta, Edmonton, CAN 2. Department of Oncology, University of Calgary 3. Department of Oncology, University of Alberta

$\square$ Corresponding author: Brock J. Debenham, debenham@ualberta.ca

Disclosures can be found in Additional Information at the end of the article

\section{Abstract}

\section{Purpose}

To compare and contrast the patterns of failure in patients with locally advanced squamous cell oropharyngeal cancers undergoing curative-intent treatment with primary surgery or radiotherapy +/- chemotherapy.

\section{Methods and materials}

Two hundred and thirty-three patients with Stage III or IV oropharyngeal squamous cell carcinoma who underwent curative-intent treatment from 2006-2012 were reviewed. The median length of follow-up for patients still alive at the time of analysis was 4.4 years. Data was collected retrospectively from a chart review.

\section{Results}

One hundred and thirty-nine patients underwent primary surgery +/- adjuvant therapy, and 94 patients underwent primary radiotherapy $+/$ - chemotherapy (CRT). Demographics were similar between the two groups, except primary radiotherapy patients had a higher age-adjusted Charleston comorbidity score (CCI). Twenty-nine patients from the surgery group recurred; 15 failed distantly only, seven failed locoregionally, and seven failed both distantly and locoregionally. Twelve patients recurred who underwent chemoradiotherapy; ten distantly alone, and two locoregionally. One patient who underwent radiotherapy (RT) alone failed distantly. Two and five-year recurrence-free survival rates for patients undergoing primary RT

Received 06/07/2016 Review began 06/19/2016 Review ended 07/14/2016 Published 07/26/2016

\section{(c) Copyright 2016}

Debenham et al. This is an open access article distributed under the terms of the Creative Commons Attribution License CC-BY 3.0., which permits unrestricted use, distribution, and reproduction in any medium, provided the original author and source are credited. were $86.6 \%$ and $84.9 \%$, respectively. Two and five-year recurrence-free survival rates for primary surgery was $80.9 \%$ and $76.3 \%$, respectively $(\mathrm{p}=0.21)$. There was no significant difference in either treatment when they were stratified by p16 status or smoking status.

\section{Conclusions}

Our analysis does not show any difference in outcomes for patients treated with primary surgery or radiotherapy. Although the primary pattern of failure in both groups was distant metastatic disease, some local failures may be preventable with careful delineation of target volumes, especially near the base of skull region.

\section{How to cite this article}

Debenham B J, Banerjee R, Warkentin H, et al. (July 26, 2016) Survival Outcomes and Patterns of Recurrence in Patients with Stage III or IV Oropharyngeal Cancer Treated with Primary Surgery or Radiotherapy. Cureus 8(7): e713. DOI 10.7759/cureus.713 
Categories: Otolaryngology, Radiation Oncology, Oncology

Keywords: oropharyngeal, hpv, oropharyngeal cancer, surgery, radiation, radiotherapy, recurrence, patterns of failure, failure

\section{Introduction}

Locally advanced oropharyngeal cancers are increasing in incidence. Although most centers throughout Canada and the United States (US) favor treating these malignancies with an organpreservation approach using combined chemoradiotherapy (CRT) [1], some centers, including ours, have a large experience treating with primary surgery followed by adjuvant therapy [2]. Recently, our center reported outcomes of our experience from the years 1998 to 2009, which appeared to show an improved disease-free survival at two years for surgery as a primary treatment compared to CRT (73.7\% vs. 57.4\%) [2]. Previous studies from Stanford and others have consistently reported three to four-year local control rates for patients treated with CRT of $90 \%$ or higher, and three-year disease-free survival rates of approximately $80 \%$ [3-8].

Due to the large discrepancy in our outcomes compared to other large academic centers, we undertook a quality assurance study looking at stage-matched patients with locally advanced oropharyngeal cancer undergoing either primary surgery or radiotherapy with an emphasis on disease-free survival, overall survival, and patterns of recurrence.

\section{Materials And Methods}

Ethics approval was obtained before initiating this study through the Health Research Ethics Board of Alberta - Cancer Committee (ETH\#26196). The patient list was obtained from the Alberta Cancer Registry (ACR). The list was created by searching for all Stage III and IV squamous cell cancers (SCC) of the oropharynx treated with primary surgery +/- adjuvant therapy or radiotherapy $+/$ - chemotherapy. The timelines used were from January 1, 2006 to December 31, 2012 and the location was Northern Alberta. All patients had CT or PET imaging of the neck and chest prior to initiation of curative-intent therapy, as well as a formal quadroscopy for biopsy of the primary site of disease.

An initial list of 333 patients was obtained from the ACR. A comprehensive chart review was undertaken, and a database was populated. A final list of 233 patients who underwent nonclinical trial, curative-intent treatment were included in the analysis. The median length of follow-up for patients still alive at the time of analysis was 4.4 years. Reasons for exclusion of the other 100 patients from the ACR were as follows: 27 patients had a non-oropharyngeal primary tumor; 27 had palliative-intent treatment (radiotherapy, chemotherapy, or best supportive care); 22 had metastases at diagnosis; 15 had their primary treatment outside of Northern Alberta; six had recurrent disease from a previous head and neck cancer (prior to 2006); two of them had Stage I or II disease; one had synchronous head and neck (H\&N) primaries; one had a non-SCC cancer; and one had been included in the registry twice.

\section{Statistical analysis}

Patient demographics, treatment factors, follow-up dates, imaging results, and pathology results were collected and anonymized. Summary statistics were calculated, including mean and standard deviations for continuous variables, and frequency and percentages for categorical variables. Recurrence-free survival (RFS) and overall survival (OS) was measured from the date of diagnosis to the date of recurrence or death. Kaplan-Meier estimates of the median RFS and OS and 95\% confidence interval $(95 \% \mathrm{CI})$ were obtained. Logistic regression was used to explore the association between factors commonly available at the time of consultation (age, histology, PS, gender) as well treatment factors for both surgery and radiation. After univariate analysis, variables significant at the $\mathrm{p}<0.10$ level were entered into 


\section{Cureus}

multivariate models. Final models selected variables significant at the $\mathrm{p}<0.05$ level. All analyses were conducted using SAS version 9.3, with $\mathrm{p}<0.05$ indicating statistical significance.

\section{Results}

\section{Patient demographics}

Patient demographics were analyzed and summarized in Table 1 below.

\begin{tabular}{|c|c|c|c|}
\hline & Primary Surgery $(n=139)$ & Primary Radiation $(n=94)$ & p-value \\
\hline Male/Female & 121/18 & $82 / 12$ & $p=0.88$ \\
\hline $\begin{array}{l}\text { Age-adjusted } \\
\text { Charleston Co- } \\
\text { morbidity Index } \\
\text { (median) }\end{array}$ & $3(95 \%$ Cl 3-4) & 4 (95\% Cl 3-4) & $p=0.046$ \\
\hline $\begin{array}{l}\text { Age at Diagnosis } \\
\text { (median) }\end{array}$ & 56 (95\% Cl 54-57) & 56 (95\% Cl 54-59) & $p=0.19$ \\
\hline AJCC Stage & $\begin{array}{l}\text { III - } 21(15.1 \%) \text { IVA - } 104(74.8 \%) \text { IVB - } \\
14(10.1 \%)\end{array}$ & $\begin{array}{l}\text { III - } 14(14.9 \%) \text { IVA }-62(65.9 \%) \text { IVB }-18 \\
(19.1 \%)\end{array}$ & $p=0.13$ \\
\hline $\begin{array}{l}\text { Clinical T-Stage } \\
\text { (RT) } \\
\text { Pathologic T-Stage } \\
\text { (Surgery) }\end{array}$ & $\begin{array}{l}\text { T1 }(21.6 \%) \\
\text { T2 }(35.3 \%) \\
\text { T3 }(20.2 \%) \\
\text { T4a }(21.6 \%) \\
\text { T4b }(1.4 \%)\end{array}$ & $\begin{array}{l}\text { T1 }(40.4 \%) \\
\text { T2 }(21.3 \%) \\
\text { T3 }(20.2 \%) \\
\text { T4a }(11.7 \%) \\
\text { T4b }(6.4 \%)\end{array}$ & $p=0.06$ \\
\hline $\begin{array}{l}\text { Clinical N-stage } \\
\text { (RT) Pathologic N- } \\
\text { Stage (Surgery) }\end{array}$ & $\begin{array}{l}\text { N0 }(6.5 \%) \\
\text { N1 }(13.8 \%) \\
\text { N2a }(11.6 \%) \\
\text { N2b }(33.3 \%) \\
\text { N2c }(28.3 \%) \\
\text { N3 }(6.5 \%)\end{array}$ & $\begin{array}{l}\text { N0 }(1.1 \%) \\
\text { N1 }(14.9 \%) \\
\text { N2a }(18.1 \%) \\
\text { N2b }(31.9 \%) \\
\text { N2c }(19.1 \%) \\
\text { N3 }(14.9 \%)\end{array}$ & $p=0.14$ \\
\hline Smoking Status & $\begin{array}{l}\text { Lifelong non-smoker - } 30(21.6 \%) \text { Former } \\
\text { smoker - } 71(51.1 \%) \text { Current smoker - } 37 \\
(26.6 \%) \text { Unknown - } 1(0.7 \%)\end{array}$ & $\begin{array}{l}\text { Lifelong non-smoker - } 19(20.2 \%) \text { Former } \\
\text { smoker - } 41(43.6 \%) \text { Current smoker - } 34 \\
(36.1 \%) \text { Unknown - } 0(0 \%)\end{array}$ & $p=0.38$ \\
\hline P16 Status & $\begin{array}{l}\text { Positive }-25(18.0 \%) \text { Negative }-8(5.7 \%) \\
\text { Unknown }-106(76.3 \%)\end{array}$ & $\begin{array}{l}\text { Positive }-26(27.7 \%) \quad \text { Negative }-5 \\
(5.3 \%) \text { Unknown }-63(67.0 \%)\end{array}$ & $p=0.21$ \\
\hline $\begin{array}{l}\text { Time from } \\
\text { Diagnosis to Initial } \\
\text { Treatment (mean, } \\
\text { days) }\end{array}$ & 74.6 & 84.4 & $p=0.03$ \\
\hline
\end{tabular}

\section{TABLE 1: Patient Demographics}




\section{Cureus}

\section{Primary surgery}

One hundred thirty-nine patients underwent primary surgery. Seventeen underwent surgery alone, 27 underwent surgery plus adjuvant radiotherapy (SRT), and 95 underwent surgery plus adjuvant chemoradiotherapy (SCRT). The reasons for patients who had surgery alone and did not receive any adjuvant treatment included patient refusal $(n=6)$, patients were not offered adjuvant therapy $(\mathrm{n}=3)$, metastases presented after surgery but prior to starting adjuvant therapy $(\mathrm{n}=4)$, patient died prior to starting adjuvant therapy $(\mathrm{n}=3)$, or poor performance status after surgery $(\mathrm{n}=1)$.

Patients at our center are routinely offered concurrent chemotherapy post-surgery for intermediate risk factors, such as T3/T4 disease, perineural invasion (PNI), lymphovascular space invasion (LVSI), or node positive disease rather than only in patients with positive margins or extracapsular extension [9-10]. There was not a significant difference in RFS or OS in patients who received SRT or SCRT. Patients began their adjuvant treatment, on average, 56 days (95\% CI $53-59$ days) post-surgery, with only $8 \%$ of patients starting within our guideline of six weeks post-surgery [11].

Twenty-nine patients from the surgery group recurred; 15 failed distantly only, seven failed locoregionally, and seven failed both distantly and locoregionally.

Regression analysis was performed, and on univariate analysis, the following variables were found to be significant, as listed below in Table 2 . 


\section{Cureus}

\begin{tabular}{|c|c|c|}
\hline Factor & Hazard Ratio & $\mathrm{p}$-value \\
\hline Nodes Positive $(0,<5,>5)$ & $>5$ nodes $-5.08(95 \% \mathrm{Cl} 2.31-11.1)$ & $p<0.0001$ \\
\hline Age Adjusted $\mathrm{Cl}$ & & NS \\
\hline Age & & NS \\
\hline AJCC Stage & & NS \\
\hline Chemotherapy Type (SCRT only) & Carboplatin - 3.35 (95\% Cl 1.29-8.64) & $p=0.013$ \\
\hline $\begin{array}{l}\text { Chemotherapy Schedule (Weekly vs every } 3 \text { weeks) } \\
\text { (SCRT only) }\end{array}$ & Weekly - 4.40 (95\% Cl 1.57-12.29) & $p=0.003$ \\
\hline Radiation Dose $(<6000,6000-6600,>6600)$ & & NS \\
\hline ECE status & $4.23(95 \% \mathrm{Cl} 1.99-9.53)$ & $p=0.0002$ \\
\hline Gender & Female $2.61(95 \% \mathrm{Cl} 1.12-6.10)$ & $p=0.04$ \\
\hline LVI status & $2.15(95 \%$ Cl 1.03-4.50) & $p=0.04$ \\
\hline Margin status & $4.11(95 \% \mathrm{Cl} 1.92-8.83)$ & $p=0.001$ \\
\hline P16 & P16 neg 4.11 (95\% Cl 1.42-11.80) & $p=0.02$ \\
\hline $\mathrm{pN}$ status & N2c $5.53(95 \%$ Cl 2.64-11.6) & $p<0.0001$ \\
\hline pT status & $\begin{array}{l}\text { T3 } 4.09(95 \% \text { Cl } 1.58-10.55) \text { T4a } 4.68(95 \% \text { Cl } \\
1.85-11.83) \\
\text { T4b } 55.3(95 \% \text { Cl } 5.67-541.61)\end{array}$ & $p=0.0004$ \\
\hline Smoking status & & NS \\
\hline Time from diagnosis to surgery & & NS \\
\hline $\begin{array}{l}\text { Time from surgery to start of radiotherapy ( }>6 \text { weeks vs } \\
<6 \text { weeks) }\end{array}$ & & NS \\
\hline Grade 3 & $3.07(95 \% \mathrm{Cl} 1.40-6.73)$ & $p=0.0052$ \\
\hline PNI status & 2.30 (95\% Cl 1.20-4.42) & $p=0.013$ \\
\hline
\end{tabular}

TABLE 2: Univariate analysis for risk factors for recurrence in patients undergoing primary surgery.

These variables were then entered into a multivariable analysis. For SCRT patients, chemotherapy schedule was not significant in the multivariate model. For all surgery patients combined, the following variables were significant on multivariate analysis, as listed in Table 3. 


\section{Cureus}

\begin{tabular}{|c|c|c|}
\hline Factor & Hazard Ratio & p-value \\
\hline Nodes Positive $(0,<5,>5)$ & $>5$ nodes $-4.72(95 \%$ Cl 1.59-13.96) & $p=0.0054$ \\
\hline Gender & Female - 5.08 (95\% Cl 2.03-12.74) & $p=0.0005$ \\
\hline P16 negative & 4.44 (95\% Cl 1.92-10.24) & $p=0.0005$ \\
\hline pT4b & $46.98(95 \%$ Cl 4.04-546.14) & $p=0.0001$ \\
\hline Chemotherapy (SCRT only) & Carboplatin - 3.35 (95\% Cl 1.29-8.64) & $p=0.013$ \\
\hline
\end{tabular}

TABLE 3: Multivariate analysis for risk factors for recurrence in patients undergoing primary surgery

\section{Primary radiotherapy}

Ninety-four patients underwent CRT $(n=84)$ or RT alone $(n=7)$. Patients who underwent RT alone did so for the following reasons: four refused chemotherapy, two patients were not chemotherapy candidates, and one patient was not offered a chemotherapy consultation. Our standard dose fractionation at our center is to deliver 6600 cGy over 30 daily fractions, based on RTOG 00-22 [12]. Univariate analysis was performed for risk factors for recurrence, and the results are summarized in Table 4. 


\section{Cureus}

\begin{tabular}{lll} 
Factor & Hazard Ratio & p-value \\
\hline Age Adjusted CCI & & NS \\
Age & & NS \\
AJCC Stage & IVB $-5.72(95 \% \mathrm{Cl} 1.93-16.96)$ & $\mathrm{p}=0.0017$ \\
Chemotherapy Type (CRT only) & $\mathrm{NS}$ \\
Chemotherapy Schedule (Weekly vs every 3 weeks) (CRT only) & $\mathrm{NS}$ \\
Radiation Dose (<6000, 6000-6600, >6600) & $\mathrm{NS}$ \\
Gender & $\mathrm{NS}$ \\
Persistent disease after primary RT treatment & $\mathrm{p}=0.0001$ \\
P16 & $9.14(95 \% \mathrm{Cl} 3.07-27.21)$ & $\mathrm{NS}$ \\
CN status & $\mathrm{N}-5.23(95 \% \mathrm{Cl} 1.76-15.45)$ & $\mathrm{p}=0.003$ \\
CT status & & $\mathrm{NS}$ \\
Smoking status & & $\mathrm{NS}$ \\
Time from diagnosis to RT & & $\mathrm{NS}$ \\
Grade & & $\mathrm{NS}$
\end{tabular}

TABLE 4: Univariate analysis for risk factors for recurrence in patients undergoing primary RT

The significant variables were entered into multivariate analysis. The results are summarized below in Table 5.

\begin{tabular}{|l|l|l}
\hline Factor & Hazard Ratio & p-value \\
\hline Stage & IVB $-4.85(95 \% \mathrm{Cl} 1.61-14.58)$ & $\mathrm{p}=0.0051$ \\
Persistent disease after RT & $7.70(95 \% \mathrm{Cl} 2.55-23.22)$ & $\mathrm{p}=0.0003$
\end{tabular}

TABLE 5: Multivariate analysis for risk factors for recurrence in patients undergoing primary RT

\section{Patterns of recurrence}

Twelve patients recurred who underwent chemoradiotherapy; ten distantly alone, and two 


\section{Cureus}

locoregionally. One patient who underwent RT alone failed distantly. Eighteen patients who recurred underwent surgery followed by chemoradiotherapy: 11 distantly alone, two locoregionally alone, and five locoregionally and distantly. Five patients failed who underwent surgery followed by radiation alone: one distantly, three locoregionally, and one locoregionally and distantly. Six patients failed who underwent surgery alone; three distantly, two locoregionally, and one locoregionally and distantly.

For the patients that received radiotherapy as part of their treatment, and failed locally or locoregionally, we analyzed their radiotherapy plans to look at the location of recurrence versus the dose in the region. The results are summarized in Table 6.

\begin{tabular}{|c|c|c|c|c|}
\hline Case & Treatment & Stage/risk factors & Failure Location & Notes \\
\hline 1 & SCRT & $\begin{array}{l}\text { T4aN2b, positive } \\
\text { surgical margins }\end{array}$ & $\begin{array}{l}\text { Base of } \\
\text { skull/pterygoid } \\
\text { plates }\end{array}$ & $\begin{array}{l}\text { Patient terminated } \mathrm{RT} \text { early, received } 50.4 \mathrm{~Gy} / 28 \text { to } \\
\text { recurrent area }\end{array}$ \\
\hline 2 & SRT & T2N2c & Sphenoid bone & $\begin{array}{l}\text { No coverage of base of skull despite level } 2 \text { nodes } \\
\text { positive }\end{array}$ \\
\hline 3 & SRT & $\begin{array}{l}\mathrm{T} 2 \mathrm{~N} 3 \text {, positive } \\
\text { margins }\end{array}$ & Near parotid & $\begin{array}{l}\text { Recurrence in } 60 \text { Gy region (no RT boost or chemo } \\
\text { (poor KPS)) }\end{array}$ \\
\hline 4 & SRT & $\begin{array}{l}\text { T1N2a, positive } \\
\text { margins, ECE }\end{array}$ & High level 2 & $\begin{array}{l}\text { High level } 2 \text { not covered despite positive lymph node } \\
\text { in level } 2 \text {, marginal miss }\end{array}$ \\
\hline 5 & SCRT & T4aN2c, ECE & Neck & Only completed $48 \mathrm{~Gy}$, quit RT \\
\hline 6 & CRT & T3N3 & Neck & In high dose RT area \\
\hline 7 & CRT & T1N3 & Neck & In high dose RT area \\
\hline
\end{tabular}

TABLE 6: Review of locoregional failures radiotherapy plans

As an example, the marginal miss in Case 4 is demonstrated in Figures 1-2 below. 


\section{Cureus}

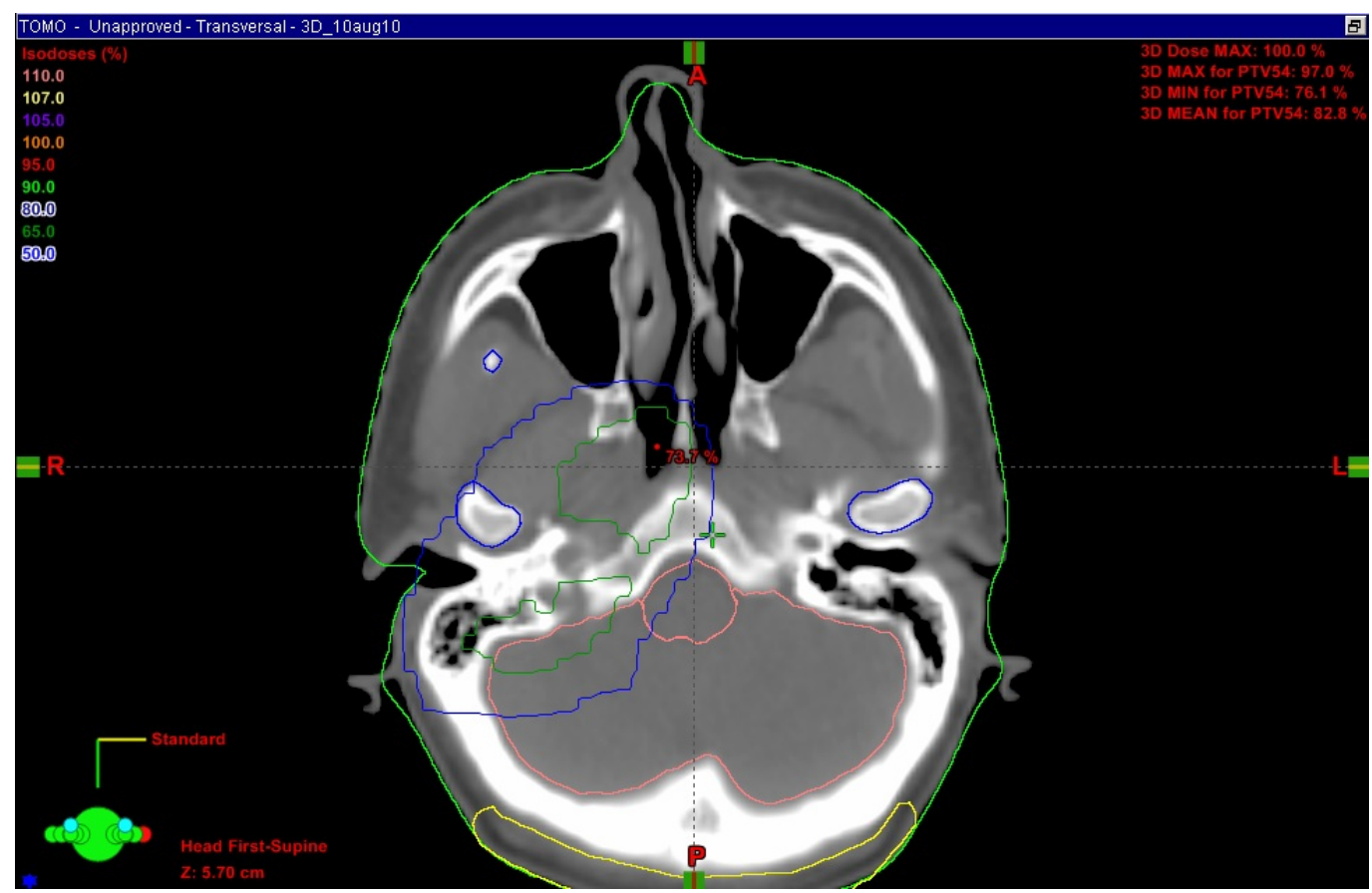

FIGURE 1: Radiotherapy plan, Case 4, marginal miss, poor coverage of high level $2 /$ base of skull.

The plan shows poor coverage (covered by less than the 95\% isodose line) at the high level 2 neck lymph nodes.

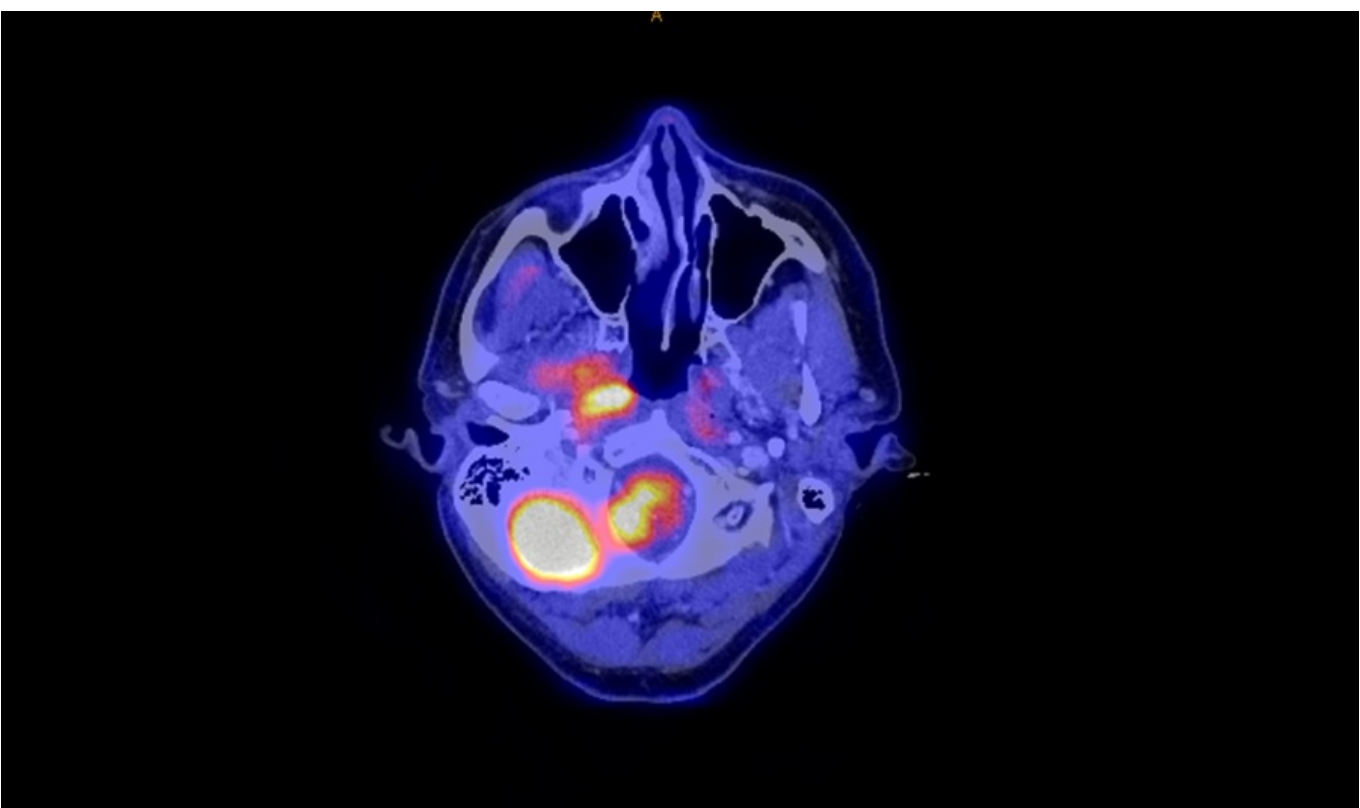

FIGURE 2: PET scan of recurrence, Case 4, marginal miss, poor coverage of high level $2 /$ base of skull.

\section{Recurrence-free survival comparison}




\section{Cureus}

Two and five-year recurrence-free survival rates for patients undergoing primary RT was and $86.6 \%$ and $84.9 \%$, respectively. Two and five-year recurrence-free survival rates for primary surgery was $80.9 \%$ and $76.3 \%$, respectively. There was no significant difference in either treatment when stratified by p16 status or smoking status. The Kaplan-Meier estimate of recurrence-free survival is shown in Figure $3(p=0.21)$.

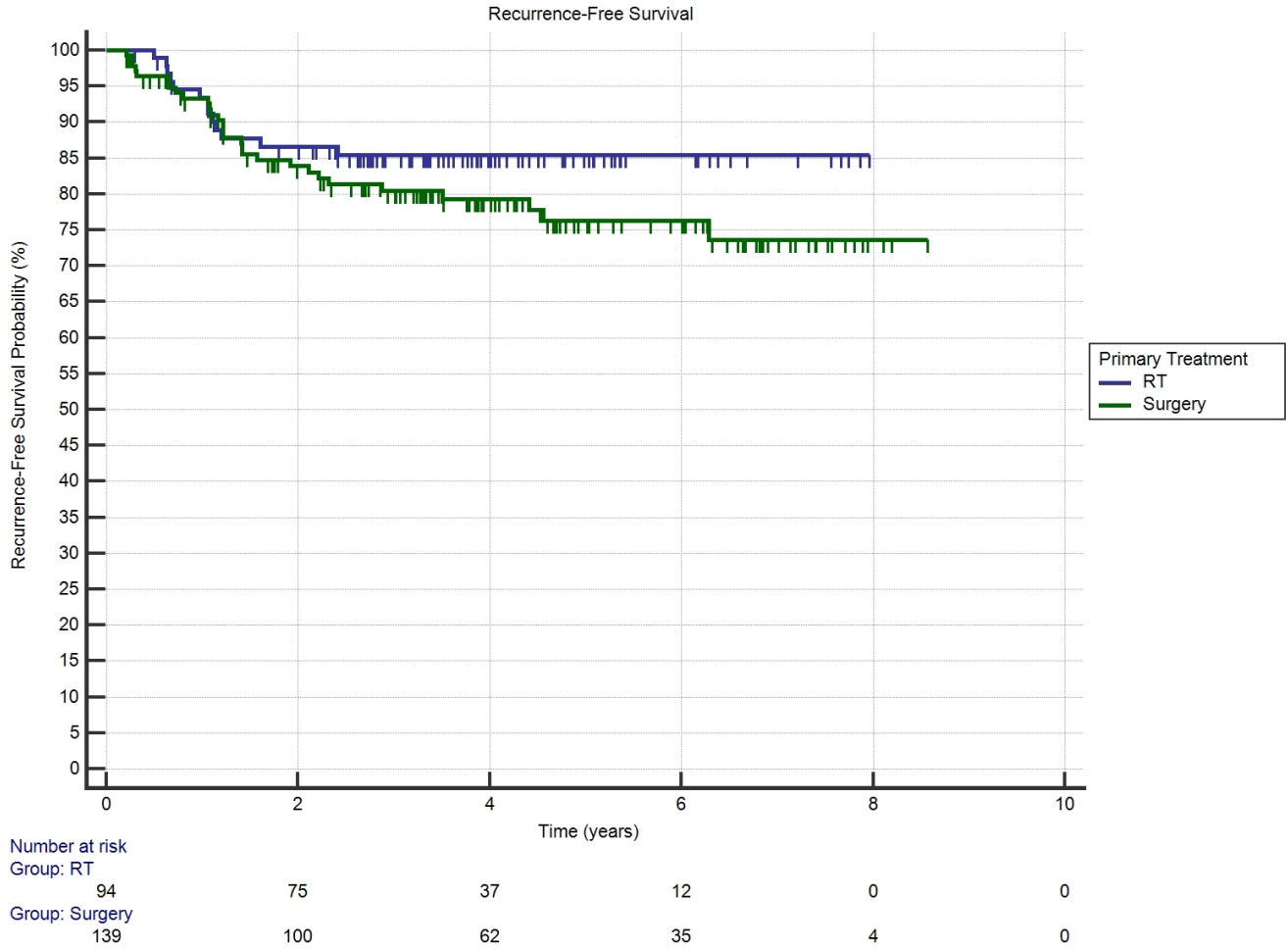

FIGURE 3: Kaplan-Meier Recurrence-Free Survival for Primary Surgery vs Primary RT

\section{Overall survival comparison}

Two and five-year overall survival rates for primary RT was $86.6 \%$ and $73.4 \%$, respectively. Two and five-year overall survival rates for primary surgery was $83.9 \%$ and $66.5 \%$, respectively ( $\mathrm{p}=0.38$ ). There was no significant difference in either treatment when stratified by p16 status or smoking status. The Kaplan-Meier estimate of recurrence-free survival is shown in Figure 4 $(\mathrm{p}=0.38)$ 


\section{Cureus}

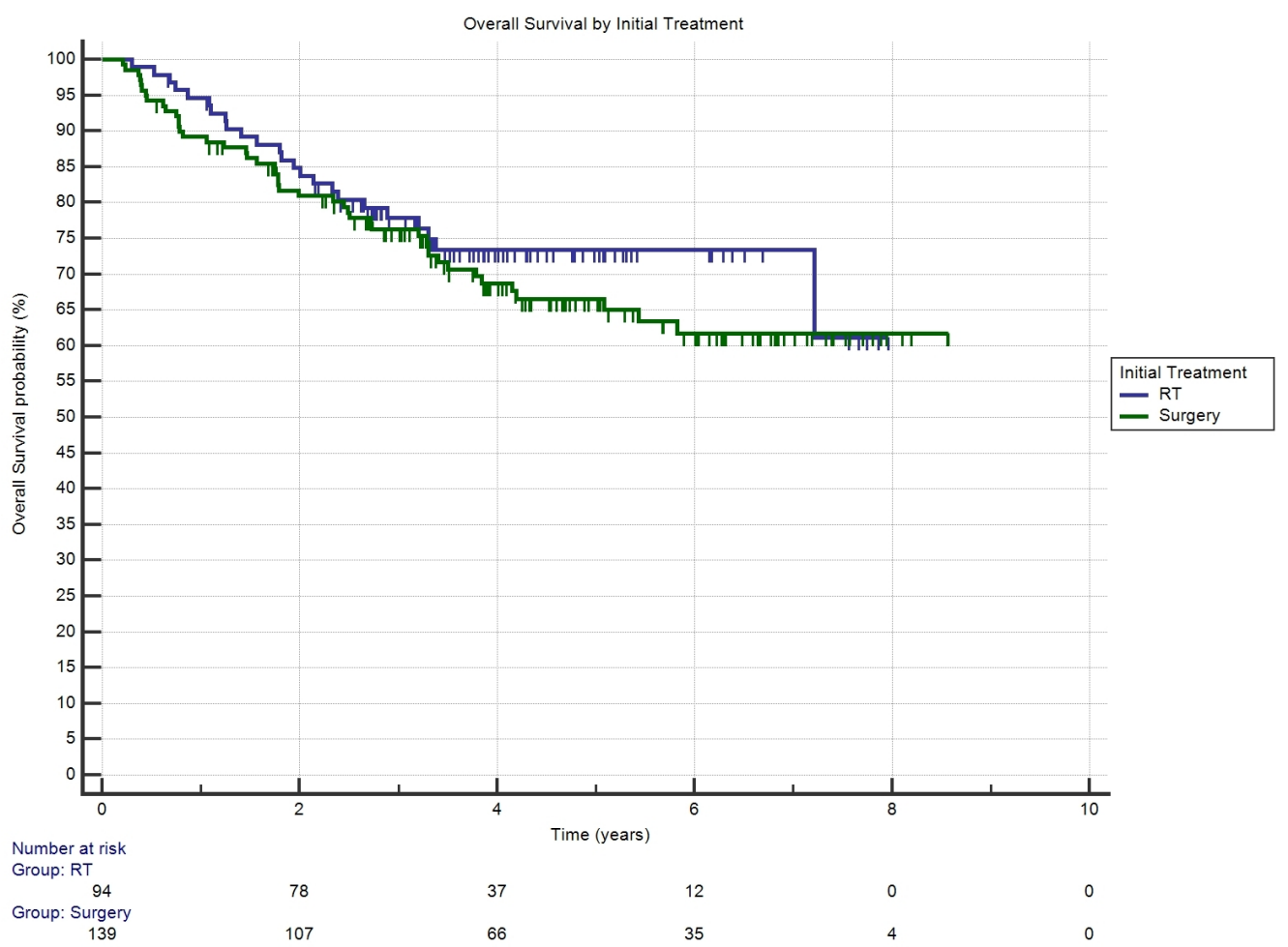

FIGURE 4: Kaplan-Meier Overall Survival for Primary Surgery vs Primary RT

\section{Causes of death}

Twenty-four patients died in the primary RT group (25.5\%). Five died of non-cancer causes (20.8\%), 11 died of oropharyngeal cancer (45.8\%), and eight died of new cancer primaries, the majority being biopsy-confirmed lung cancer (32.0\%). Forty-six patients died in the primarysurgery group (33.1\%). Sixteen (34.8\%) died of non-cancer causes, 24 died of oropharyngeal cancer (52.2\%), and six died of a new cancer primary (13.0\%).

\section{Discussion}

Our results are consistent with other large academic centers in patients who undergo CRT as primary treatment for locally advanced oropharyngeal carcinoma with two and five-year RFS rates of $86.6 \%$ and $84.9 \%$. In comparison to our centre's previously published results, we found that the percentage of patients undergoing RT alone was not as high (18.3\% in previous results vs $3 \%$ in this cohort) [2]. This likely reflects the fact that patients receiving RT alone was likely palliative, and these patients should have been removed from the previous study.

Weaknesses of this study include bias in treatments, as patients who underwent primary RT compared to surgery had higher Charleston Co-Morbidity Index (CCI) [13], and a higher proportion of $\mathrm{T} 4 \mathrm{~b}$ disease. We are missing human papilloma virus (HPV) status on the majority of our patients, as our centre did not routinely test for p16 status until 2010-2011, which limits comparisons on comparing modalities when stratifying by HPV status. Additionally, we have no data in regards to functional outcomes of our patients, or the cost difference in treatment between the two groups. 
Although the dominant pattern of failure for patients treated with both primary surgery and radiotherapy remains a distant failure, it may have been possible to prevent some local recurrences with adjustment of the radiotherapy plans. Specifically, we had two recurrences at the base of the skull and one near the parotid gland in primary surgery patients who underwent adjuvant treatment. This phenomenon has been described before by Eisbruch, et al. [14]; therefore, it is important to ensure that this coverage is achieved during radiotherapy planning and QA processes. There were more local recurrences in the surgery group compared to the radiotherapy groups in our study. We do not have a good explanation for this, except perhaps that after surgery oxygenation to the tumor bed may be altered, and perhaps adjuvant radiotherapy is not as effective with the altered oxygenation to the post-surgical bed.

The primary pattern of failure in both primary surgery or radiotherapy patients was distant. This pattern was in many other studies. Results from RTOG 0234 demonstrated a decreased rate of distant metastatic disease in patients receiving docetaxel chemotherapy rather than standard cisplatin chemotherapy [15]. This hypothesis is being further tested in high-risk postoperative patients in RTOG 1216, which is currently open to accrual [16]. Our standard chemotherapy offered to these patients may change in the future based on the results of RTOG 1216 and will hopefully alter the patterns of failure for these patients.

\section{Conclusions}

Our analysis does not show any difference in outcomes for patients treated with primary surgery or radiotherapy. Although the primary pattern of failure in both groups was distant metastatic disease, some local failures may be preventable with careful delineation of target volumes, especially near the base of skull region.

\section{Additional Information \\ Disclosures}

Human subjects: Consent was obtained by all participants in this study. Health Research Ethics Board of Alberta - Cancer Committee issued approval 26196. Animal subjects: All authors have confirmed that this study did not involve animal subjects or tissue. Conflicts of interest: In compliance with the ICMJE uniform disclosure form, all authors declare the following: Payment/services info: All authors have declared that no financial support was received from any organization for the submitted work. Financial relationships: All authors have declared that they have no financial relationships at present or within the previous three years with any organizations that might have an interest in the submitted work. Other relationships: All authors have declared that there are no other relationships or activities that could appear to have influenced the submitted work.

\section{References}

1. Wilson L, Enepekides D, Higgins K: Management of oropharyngeal cancer: a cross-sectional review of institutional practice at a large Canadian referral centre.. Journal of Otolaryngology

- Head \& Neck Surgery. 2014, 43:19. 10.1186/1916-0216-43-19

2. O' Connell D, Seikaly H, Murphy R, et al.: Primary surgery versus chemoradiotherapy for advanced oropharyngeal cancers: a longitudinal population study. Journal of Otolaryngology Head \& Neck Surgery. 2013, 42:31. 10.1186/1916-0216-42-31

3. Setton J, Caria N, Romanyshyn J, et al.: Intensity-modulated radiotherapy in the treatment of oropharyngeal cancer: an update of the Memorial Sloan-Kettering Cancer Center experience. International journal of radiation oncology, biology, physics. 2012, 82: 291-298. 10.1016/j.ijrobp.2010.10.041

4. Setton J, Lee NY, Riaz N, et al.: A multi-institution pooled analysis of gastrostomy tube dependence in patients with oropharyngeal cancer treated with definitive intensitymodulated radiotherapy. Cancer. 2015, 121:294-301. 10.1002/cncr.29022 
5. Ang KK, Zhang Q, Rosenthal DI, et al.: Randomized phase III Trial of concurrent accelerated radiation plus cisplatin with or without cetuximab for stage III to IV head and neck carcinoma: RTOG 0522. Journal of Clinical Oncology. 2014, 32:2940-2950. 10.1200/JCO.2013.53.5633

6. Goenka A, Morris LG, Rao SS, et al.: Long-term regional control in the observed neck following definitive chemoradiation for node-positive oropharyngeal squamous cell cancer. International Journal of Cancer. 2013, 133:1214-1221. 10.1002/ijc.28120

7. Huang K, Xia P, Chuang C, et al.: Intensity-modulated chemoradiation for treatment of stage III and IV oropharyngeal carcinoma: the University of California-San Francisco experience. Cancer. 2008, 113:497-507. 10.1002/cncr.23578

8. Daly ME, Le QT, Maxim PG, et al.: Intensity-modulated radiotherapy in the treatment of oropharyngeal cancer: clinical outcomes and patterns of failure. International journal of radiation oncology, biology, physics. 2010, 76:1339-46. 10.1016/j.ijrobp.2009.04.006

9. Bernier J, Cooper JS, Pajak TF, et al.: Defining risk levels in locally advanced head and neck cancers: a comparative analysis of concurrent postoperative radiation plus chemotherapy trials of the EORTC (\#22931) and RTOG (\# 9501). Head \& Neck. 2005, 27:843-850. 10.1002/hed.20279

10. Bernier J, Cooper IS: Chemoradiation after surgery for high-risk head and neck cancer patients: how strong is the evidence?. The Oncologist. 2005, 10:215-224.

10.1634/theoncologist.10-3-215

11. The Organization and Delivery of Healthcare Services for Head and Neck Cancer Patients . (2015). Accessed: June 6, 2016: http://www.albertahealthservices.ca/assets/info/hp/cancer/ifhp-cancer-guide-hn001-organization.pdf.

12. Eisbruch A, Harris J, Garden AS, et al.: Multi-institutional trial of accelerated hypofractionated intensity-modulated radiation therapy for early-stage oropharyngeal cancer (RTOG 00-22). International journal of radiation oncology, biology, physics. 2010, 76:13331338. 10.1016/j.ijrobp.2009.04.011

13. Habbous S, Harland LT, La Delfa A, et al.: Comorbidity and prognosis in head and neck cancers: Differences by subsite, stage, and human papillomavirus status. Head \& Neck. 2014, 36:802-810. 10.1002/hed.23360

14. Eisbruch A, Marsh LH, Dawson LA, et al.: Recurrences near base of skull after IMRT for headand-neck cancer: implications for target delineation in high neck and for parotid gland sparing. International journal of radiation oncology, biology, physics. 2004, 59:28-42. doi:10.1016/j.ijrobp.2003.10.032

15. Harari PM, Harris J, Kies MS, et al.: Postoperative chemoradiotherapy and cetuximab for highrisk squamous cell carcinoma of the head and neck: Radiation Therapy Oncology Group RTOG-0234. Journal of Clinical Oncology. 2014, 32:2486-2495. 10.1200/JCO.2013.53.9163

16. Radiation therapy with cisplatin, docetaxel, or cetuximab after surgery in treating patients with stage iii-iv squamous cell head and neck cancer. (2016). Accessed: June 6, 2016: http://clinicaltrials.gov/show/NCT01810913. 